\title{
Clinical Evaluation of Radiotherapy for Graves' Ophthalmopathy
}

\author{
Junji KONISHI, Yasuhiro IIDA, Kanji KASAGI, TAKashi MISAKI, \\ Keisuke ARAI, Keigo ENDO, Tsugio AMEMIYA*, \\ Mitsuyuki ABE** AND Kanji TORIZUKA
}

Department of Nuclear Medicine, Ophthalmology* and Radiology**, Kyoto University School of Medicine, Sakyo-ku Kyoto 606

\begin{abstract}
Seventeen patients with moderately severe ophthalmopathy due to Graves' disease were treated by cobalt or supervoltage radiotherapy. All patients complained of diplopia. The mean proptosis value was $21.4 \mathrm{~mm}$. Three patients $(18 \%)$ showed good response, $7(41 \%)$ moderate and 7 minimal or no response. Improvement was noted mainly in soft tissue changes and diplopia, while proptosis decreased in only 5 patients. All except one patient who had marked extraocular muscle involvement revealed by computed tomography responded to treatment. These data indicate that radiotherapy may be indicated in patients with progressive opthalmopathy, especially in those who are associated with extraocular muscle enlargement.
\end{abstract}

Many data support the concept that Graves' ophthalmopathy is related to an autoimmune disorder (Kriss et al., 1975; Jacobson and Gorman, 1984), but its precise pathogenesis remains to be elucidated. A variety of therapeutic approaches have been proposed for this condition including systemic steroid (Brown et al., 1963; Werner, 1966), orbital irradiation (Donaldson et al., 1973; Corvington et al., 1977 : Teng et al., 1980), and plasmapheresis (Dandona et al., 1979), to suppress immune reaction. Among them external orbital irradiation is one which has been employed sporadically for some 50 years. A substantial improvement has been reported by Kriss and coworkers (Donaldson et al., 1973; Kriss et al., 1975) and Corvington et al. (1977) with supervoltage orbital radiotheraphy. However, the

Received April 15, 1986 results obtained by Teng et al. (1980) were somewhat disappointing, with improvement in only $35 \%$ of the patients. In Japan malignant ophthalmopathy requiring any treatment is reported to be associated with $0.8 \%$ of Graves' disease (Torizuka et al., 1981). However, only a limited number of patients treated by this method have been reported (Yamamoto et al., 1982). The present paper reports our results with this method of treatment in 17 patients with moderately severe ophthalmopathy.

\section{Patients and Methods}

\section{Patients}

Seventeen patients (12 males and 5 females) were diagnosed as having malignant exophthalmos, according to the diagnostic criteria of the Hormone Receptor Disease Research Committee, Japan (Torizuka et al., 1981). The clinical data 


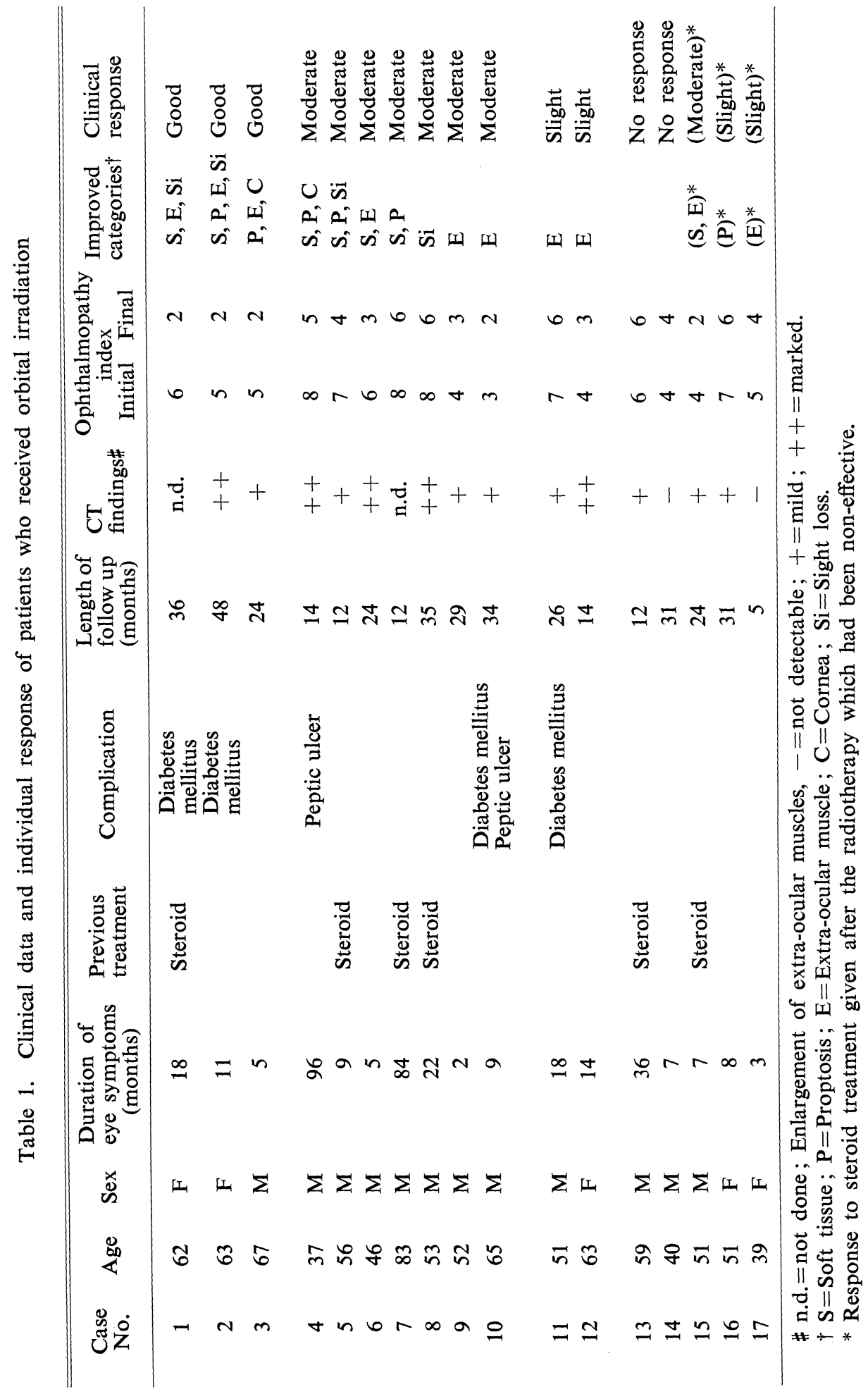


for the patients are shown in Table 1. One patient (case 8) was suffering from ophthalmic Graves' disease (Hall et al., 1970) and sixteen from Graves' disease. The latter patients were either euthyroid after radioactive iodine therapy with or without thyroxine $(n=2)$, or stabilized on methimazole $(n=14)$. The mean value for proptosis was $21.4 \mathrm{~mm}$ (ranging from 17-27 mm).

The extent of eye involvement was evaluated by physical examination, exophthalmometry, tests for extraocular muscle function, retinoscopy, tests of visual field and acuity, corneal examination and coordiometry. Exophthalmometry was carried out by one observer using one Hertel exophthalmometer to minimize the error in the measurement. Computed tomography of the orbit was performed in all except 2 cases (Table 1). Both transaxial and coronal scans were routinely obtained, and the latter was mainly used for evaluation of the enlargement of extraocular muscles. Any muscle, the thickness of which was greater than the diameter of the optic nerve, was judged hypertrophic. When the thickness was more than twice as great as the diameter of the optic nerve, enlargement of muscles was classified as marked.

Ocular changes were quantitated before and after treatment with an ophthalmopathy index, based on the American Thyroid Association's classification of eye changes in Graves' disease (Werner, 1969), as proposed by Donaldson et al. (1973), with minor modifications concerning the evaluation of proptosis (Table 2).

The ophthalmopathy index (i.e. the sum of the scores of each class) ranged from 3 to 8 , with a mean pretreatment index of 5.8. In addition to the variation in the ophthalmopathy index, the results of treatment were also graded on clinical grounds as good, moderate, slight and no response, according to the criteria of Donaldson et al. (1973).

Table 2. Methods of calculating ophthalmopathy index

\begin{tabular}{lc}
\hline \multicolumn{2}{c}{$\begin{array}{l}\text { Ophthalmopathy index }=\text { sum of scores in } 5 \\
\text { categories }\end{array}$} \\
\hline $\begin{array}{l}\text { Soft tissue } \\
\text { Proptosis* }\end{array}$ \\
$\begin{array}{l}\text { Score for each : } \\
\text { Minimal }=1\end{array}$ \\
$\begin{array}{l}\text { Cornea } \\
\text { Sight loss }\end{array}$ \\
$\begin{array}{l}\text { Moderate }=2 \\
\text { Score for proptosis : } 20 \sim 21 \mathrm{~mm}=1 ; \\
21.5 \sim 24 \mathrm{~mm}=2 ;>24 \mathrm{~mm}=3\end{array}$
\end{tabular}

\section{Radiotherapy procedure}

Orbital irradiation was performed with a cobalt radiotherapy unit in 3 patients (cases 1 , 4 and 7) and by an x-ray beam with an energy of $10 \mathrm{MeV}$ generated by a linear accelerator in 14 other patients.

The radiation field was $4 \times 5 \mathrm{~cm}$. Each field was angled posteriorly either $10^{\circ}$ in the case of cobalt irradiation or $5^{\circ}$ in the case of supervoltage irradiation to avoid irradiating the contralateral lens. The isodose distribution, evaluated by computed tomography showed that the dose delivered to the lens, cornea, pituitary, and hypothalamus was less than 5\%. All patients received the radiotherapy as in-patients.

Ten daily doses of 200 rads to each eye were given in 2 weeks, with a cumulative dose of 2000 rads except for 2 patients (cases 7 and 13) who received 4,000 and 3,000 rads, respectively. All patients were treated bilaterally. After the treatment, the patients were followed up at biweekly intervals for 1 month and then monthly intervals. The mean duration of follow-up was 24 months, the range being 5-48 months (Table 1). Statistical analyses were carried out by Student's paired or unpaired two-tailed $t$-test.

Three cases whose symptoms were not improved by radiotherapy were given successive corticosteroid treatment, 1 week after radiation. The treatment was started with $40 \mathrm{mg}$ prednisolone daily for 1 week. The dose was tapered by $5 \mathrm{mg}$ every 1-2 weeks. It was discontinued after 3 months.

\section{Results}

The overall clinical response and change in the mean ophthalmopathy indices are shown in Table 3 . Of 17 patients three achieved good results, 7 moderate and 7 minimal or no response. Thus, a significant decrease in ophthalmopathy indices was observed in $59 \%$ of the patients. None became worse, although transient deterioration of lid edema was noted in two patients (cases 6 and 9) during the first week after therapy. Any response which occurred usually started after the first week of treatment and reached a peak within 3 to 4 weeks after treatment. Thus, beneficial ef- 

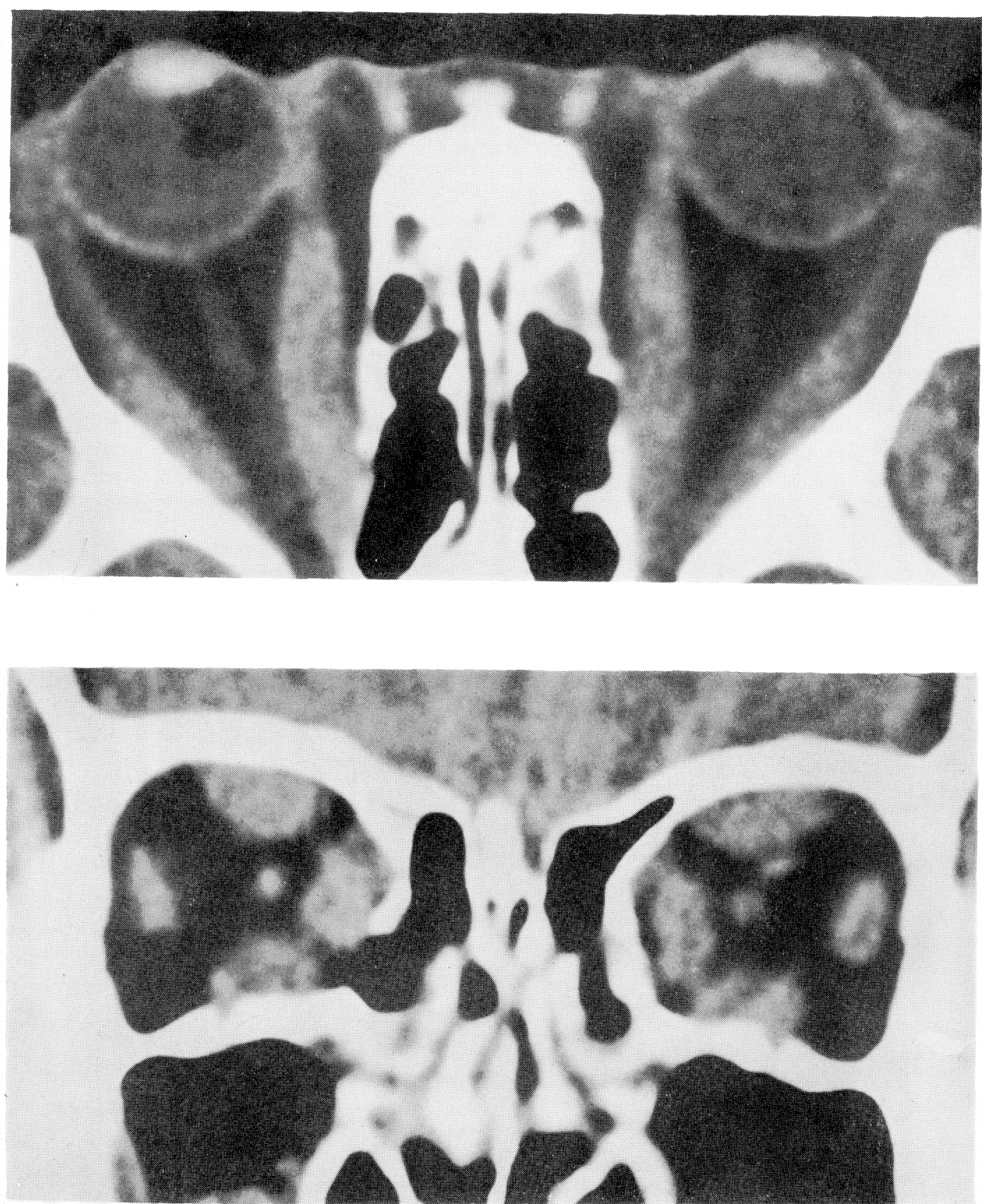

Fig. 1. Pre- (left) and postradiation therapy (right) computed tomographic scan of case 2 . Upper panel, transaxial scan; lower panel, coronal scan.

Decrease in the grade of proptosis and extraocular muscle enlargement was observed $\nearrow$ 

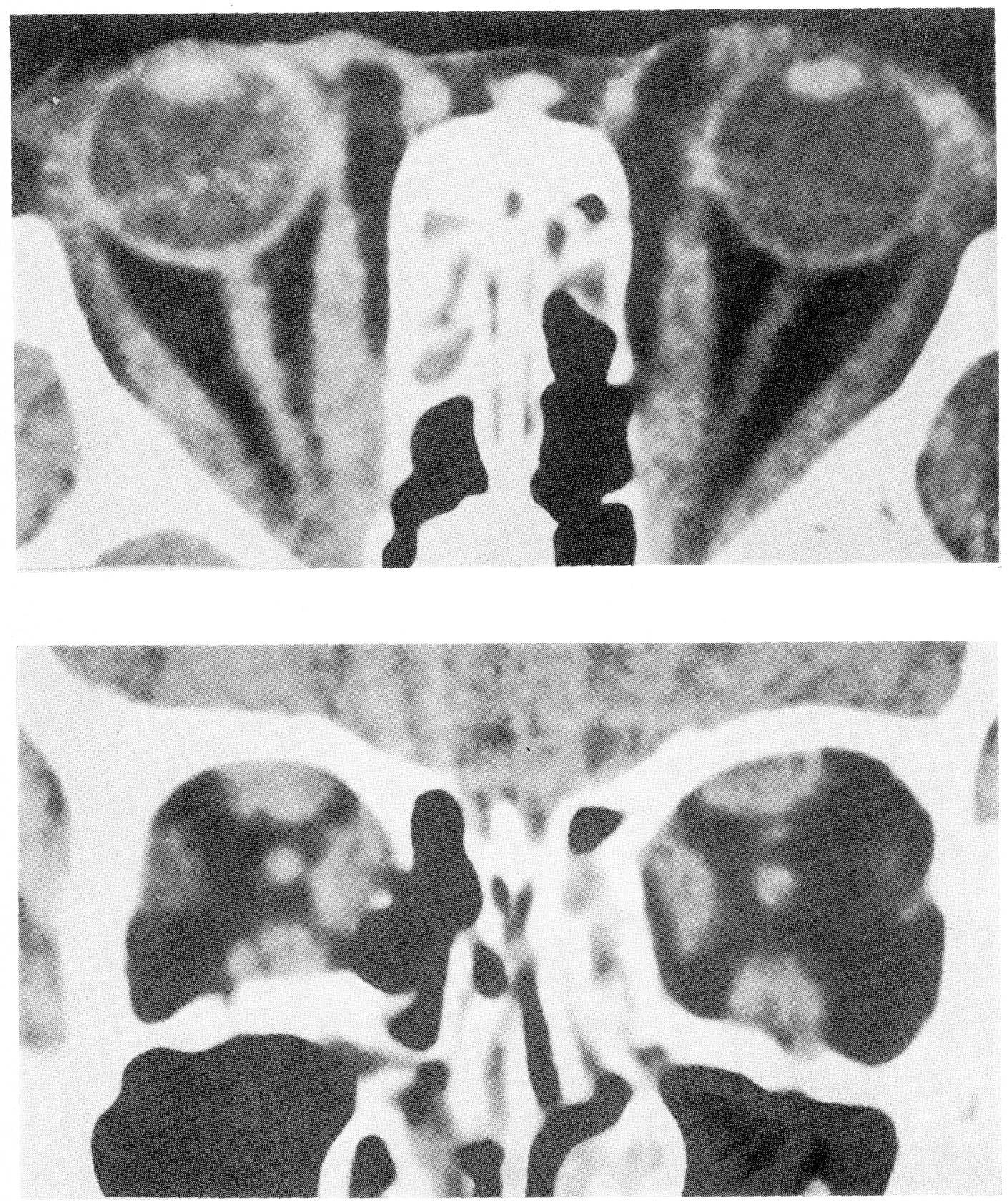

in transaxial and coronal scan, respectively, one week after treatment concomitant with clinical improvement. 
Table 3. Comparison of clinical response to radiotherapy with changes in mean ophthalmopathy index

\begin{tabular}{|c|c|c|c|c|c|}
\hline \multirow{2}{*}{$\begin{array}{l}\text { Clinical } \\
\text { response }\end{array}$} & \multirow{2}{*}{$\begin{array}{l}\text { No. of } \\
\text { patients } \\
\text { (and \%) }\end{array}$} & \multirow{2}{*}{$\begin{array}{l}\text { Mean } \\
\text { duration of } \\
\text { eye symptoms } \\
\text { (months) }\end{array}$} & \multicolumn{3}{|c|}{$\begin{array}{l}\text { Mean } \\
\text { ophthalmopathy index }\end{array}$} \\
\hline & & & Initial & Final & Change \\
\hline Good & $3(18 \%)$ & 11 & 5.3 & 2 & $\begin{array}{l}-3.3 \\
(\mathrm{p}<0.025)\end{array}$ \\
\hline Moderate & $7(41 \%)$ & 32 & 6.3 & 4.1 & $\begin{array}{l}-2.2 \\
(\mathrm{p}<0.005)\end{array}$ \\
\hline Slight & $2(12 \%)$ & 16 & 5.5 & 4.5 & -1.0 \\
\hline No response & $5(29 \%)$ & 12 & 5.2 & 5.2 & 0 \\
\hline Worse & $0(0 \%)$ & 0 & 0 & 0 & 0 \\
\hline
\end{tabular}

fects, if any, were generally obtained within one to 2 months after treatment. However, in two patients with good response (cases 2 and 3) palpebral puffiness decreased and corneal ulceration healed 10 and 6 months after treatment, respectively. Initial subjective improvement was noted by many patients even at the end of the first week of treatment: some felt their eye movement smoother with a decrease in the grittiness, while in others retrobulbar discomfort was partially relieved.

The individual responses to treatment are shown in detail in Table 1 . In general, soft tissue changes responded most readily to treatment. Proptosis decreased (more than $2 \mathrm{~mm}$ ) in only 5 cases. One patient receiving oral prednisolone (case 8 ) was able th reduce the dosage from $20 \mathrm{mg} /$ day to $2.5 \mathrm{mg} /$ day after radiotherapy. Although improvement in diplopia was noted in 8 patients, none of the 4 patients whose symptoms persisted more than 18 months before treatment experienced any improvement in ophthalmoplegia.

Computed tomography of the orbit revealed extraocular muscle enlargement in 13 out of 15 patients studied. Follow-up examination at one week after irradiation showed some improvement in 4 of 13 patients, 2 with good and 2 with moderate response (cases 2, 3, 5 and 6) (Fig. 1). Among these 4 patients, 3 accompanied with a decrease in proptosis and 3 with an improvement in diplopia. Two patients, in whom no enlargement of extraocular muscle was noted, showed no objective improvement, while 4 out of five patients who had marked swelling of the eye muscles showed moderate or good response.

The effectiveness of the therapy appeared similar whether patients had previously been treated with steroid or not. In 2 patients (cases 7 and 13) additional radiation treatment was given 2 months after the standard treatment but no significant improvement was obtained with the second treatment. Among 3 patients, who did not improve after radiotherapy and were given prednisolone (cases 15-17), one showed moderate response.

\section{Discussion}

In the present study, $59 \%$ of the patients had good or moderate response to orbital irradiation. Although the results were not as good as those by Donaldson et al. (1973) who reported that $65 \%$ of their patients had good to excellent response, they were much better than those by Teng et al. (1980) who 
reported that only $35 \%$ had moderate response. The difference might partly be explained by the fact that our patients had shorter duration of eye involvement which was also more severe than Teng's cases. Ophthalmopathy indices in the present series ranged from 3 to 8 , while those in cases studied by Donaldson et al., were 4-12, and those in Teng et al. 2-7.

Treatment was more effective for soft tissue involvement and newly developed ophthalmoplegia, while proptosis and long standing ophthalmoplegia were less responsive as previously suggested by other authors (Donaldson et al., 1973 ; Teng et al., 1980). All patients with good response had symptoms for less than 2 years and their ophthalmopathy was moderately severe (indices 5 or 6). Similar to the results reported by Teng et al. (1980) less severe cases responded rather poorly. Among five cases whose indices were 3 or 4 , only 2 responded, while among 6 cases whose indices were 7 or 8,4 cases responded.

Recently, orbital computed tomography has been widely used in assessing the involvement of extraocular muscle (Enzmann, et al., 1979). In our study, the grade of extraocular muscle enlargement was predictive of the response to treatment. In cases without notable muscle enlargement on computed tomography, no improvement was seen. The findings are compatible with the concept that the effect of radiation is mainly due to the suppressive effect on extraocular muscle swelling (Donaldson et al., 1973). The diminution of muscle volume after treatment was directly confirmed by computed tomography in 4 cases who showed clinical response.

Steroid therapy has long been applied to this condition (Brown et al., 1963; Werner, 1966), but its effect is often transient and the treatment is contraindicated in patients who have complications such as diabetes mellitus and peptic ulcer. In the initial phase of the present study, we treated patients having such complications and those who had not responded to steroid therapy. The results obtained in these patients encouraged us to extend the radiotherapy as the first choice even in uncomplicated cases. The effect of the treatment was not transient and as was found in the previous studies (Donaldson et al., 1973; Corvington et al., 1977 ; Teng et al., 1980 ; Yamamoto et al., 1982), no worsening or adverse effect was noted. As to the efficacy of the treatment in patients who had been treated with steroid hormone, 4 out of 6 such patients responded to radiotherapy. Yamamoto et al. (1982) reported the result of 9 patients among whom 7 had previous treatment with either steroid or plasmapheresis. Their result was remarkable in that 5 patients $(56 \%)$ achieved good or fair results. From these findings radiotherapy may be indicated even after other treatments.

Recently Bartalena et al. (1983) reported that the combined therapy with systemic corticosteroid and orbital radiation is a useful therapeutic method for Graves' ophthalmopathy. We tried to give prednisolone to see a beneficial effect in 3 patients who did not improve after radiotherapy. A beneficial effect was observed in all of the patients but the effect was minimal in two of them. Although the number of cases is still limited, steroid treatment may be added in cases who do not respond to radiotherapy.

In conclusion, our results showed that orbital irradiation was of benefit in $59 \%$ of patients with moderately severe ophthalmopathy. It was especially effective in cases with marked swelling of extraocular muscles detected by computed tomography. Therefore the treatment may be especially indicated in moderately severe cases accompanied with extraocular muscle enlargement. 


\section{Acknowledgement}

This study was supported in part by a Research Grant for Intractable Diseases, Ministry of Health and Welfare, Japan. We are grateful to Miss K. Aoki for secretarial assistance.

\section{References}

Bartalena, L., C. Marcocci, L. Chiovato, M. Laddaga, G. Lepri, D. Andreani, G. Cavallacci, L. Baschieri and A. Pinchera (1983). Orbital cobalt irradiation combined with systemic corticosteroids for Graves' ophthalmopathy: Comparison with systemic corticosteroids alone. J. Clin. Endocrinol. Metab. 56, 1139-1144.

Brown, J., J. W. Corburn, R. A. Wigod, J. M. Hiss and J. T. Dowling (1963). Adrenal steroid therapy of severe infiltrative ophthalmopathy of Graves' disease. Am. J. Med. 34, 786-795.

Corvington, E. E., L. Lobes and A. Sudarsanam (1977). Radiation therapy for exophthalmos. Report of seven cases. Radiology 122, 797799.

Dandona, P., N. J. Marshall, S. P. Bidsey, A. Nathan and C. W. H. Harvard (1979). Successful treatment of exophthalmos and pretibial myxedema with plasmapheresis. $\mathrm{Br}$. Med. J. 1, 374-379.

Donaldson, S. S., M. A. Bagshaw and J. P. Kriss (1973). Supervoltage orbital radiotherapy for Graves' ophthalmopathy. J. Clin. Endocrinol. Metab. 37, 276-285.

Enzmann, D. R., S. S. Donaldson and J. P. Kriss
(1979). Appearance of Graves' disease on orbital computed tomography. J. Comput. Assist. Tomogr. 3, 815-819.

Hall, R., D. Doniach, K. Kirkham and D. ElKabir (1970). Ophthalmic Graves' disease. Diagnosis and pathogenesis. Lancet 1, 375378.

Jacobson, D. H. and C. A. Gorman (1984). Endocrine ophthalmopathy: Current ideas concerning etiology, pathogenesis, and treatment. Endocr. Rev. 5, 200-220.

Kriss, J. P., J. Konishi and M. Herman (1975). Studies on the pathogenesis of Graves' ophthalmopathy (with some related observations regarding therapy). Recent Prog. Horm. Res. $31,533-566$.

Teng, C. S., A. L. Crombie, R. Hall and W. M. Ross (1980). An evaluation of supervoltage orbital irradiation for Graves' ophthalmopathy. Clin. Endocrinol. 13, 545-551.

Torizuka, K., H. Imura, J. Konishi, M. Inada, Y. Furukawa, S. Yoshida, S. Nagataki, K. Shizume, Y. Ichikawa, T. Yamada, Y. Akazawa, N. Amino, T. Fujita, E. Ogata, K. Itoh, K. Kuma and A. Noguchi (1981). A statistical survey on Japanese patients with malignant exophthalmos. Folia Endocrinol. Jpn. 57, 1-16. (in Japanese).

Werner, S. C. (1966). Prednisolone in emergency treatment of malignant exophthalmos. Lancet 1, 1004-1007.

Werner, S. C. (1969). Classification of the eye changes of Graves' disease. J. Clin. Endocrinol. Metab. 29, 982-984.

Yamamoto, K., K. Saito, T. Takai and S. Yoshida (1982). Treatment of Graves' ophthalmopathy by steroid therapy, orbital radiation therapy, plasmapheresis and thyroxine replacement. Endocrinol. Japon. 29, 495-501. 